\title{
PATHOLOGY OF FOWL PARATYPHOID AND MOLECULAR DETECTION OF ITS PATHOGEN IN LAYER CHICKENS
}

\author{
J. Alam1, T. Chakma' , M. S. Islam ${ }^{3}$, M. T. Islam², M. A. H. N. A. Khan ${ }^{4}$ \\ M. T. Islam ${ }^{5}$ and M. G. Haider ${ }^{2 *}$
}

\begin{abstract}
The study was aimed to ascertain the pathology of fowl paratyphoid and molecular detection of its causal agent (Salmonella spp) in chickens. Pathological and swab samples were collected from layers in Gazipur district, Bangladesh. For observing the gross and microscopic lesions of different organs necropsy and histopathology were done, and to isolate and identify the Salmonella spp, different bacteriological tests and Polymerase Chain Reaction (PCR) were performed. Swabs from 150 chickens showed $66 \%$ of salmonellosis. Gram's staining of isolated bacteria showed pink colored rod shaped bacilli. In biochemical tests, Salmonella fermented dextrose, maltose, xylose, arabinose, dulcitol, mannitol except lactose and sucrose. Investigation of gross lesions at necropsy revealed hemorrhage and congestion in intestine, liver, spleen and ovaries. Necrotic foci were found in liver and spleen, and button like ulceration in cecal tonsils as well. Microscopic lesions included hemorrhage and focal necrosis in liver and spleen. Congestion and infiltrations of inflammatory cells were observed in small intestine. Ovary was hemorrhagic and there was infiltration of heterophils. Biochemically positive and isolated Salmonella organisms were confirmed by PCR method using invA and IE1 primers. The final results showed that a total of $91.7 \%$ Salmonella suspected cultures were confirmed as Salmonella Enteritidis.
\end{abstract}

Keywords: Samonella, histopathology, Gram stain, hemorrhage, inflammatory.

\section{Introduction}

Bangladesh is one of the highly populated country of the world, having 150 million people within the area of 147,570 square kilometers (Islam, 2014). Poultry industry in Bangladesh plays a vital role in the rural socioeconomic system by contributing significantly on economic growth and simultaneously creating numerous employment opportunities. It is well known that poultry diseases are the major constraints for the development of poultry industry in Bangladesh (Karim, 2014). Major bacterial diseases which cause serious economic loss in poultry industries include

\footnotetext{
${ }^{1}$ Department of Animal Science, Faculty of Agriculture, Exim Bank Agricultural University Bangladesh, Chapainawabganj-6300, Bangladesh. ${ }^{2}$ Department of Pathobiology, Faculty of Veterinary Medicine and Animal Science, Bangabandhu Sheikh Mujibur Rahman Agricultural University, Gazipur 1706, Bangladesh. ${ }^{3}$ Department of Microbiology and Public Health, Faculty of Veterinary Medicine and Animal Science, Bangabandhu Sheikh Mujibur Rahman Agricultural University, Gazipur 1706, Bangladesh. ${ }^{4}$ Department of Pathology, Faculty of Veterinary Medicine, Bangladesh Agricultural University, Mymensingh 2202, Bangladesh. ${ }^{5}$ Institute of Biotechnology and Genetic Engineering Bangabandhu Sheikh Mujibur Rahman Agricultural University, Gazipur 1706, Bangladesh. *Corresponding author: ghaider@bsmrau.edu.bd
} 
salmonellosis, omphalitis, colibacillosis, infectious coryza and mycoplasmosis prevailing in Bangladesh. Among the diseases, salmonellosis is one of the major problems because it can be transmitted vertically. Salmonellosis has been found in all ages of poultry. It is a problem of economic concern from all production phase to marketing stage (Rahman, 2007). There are a large number of Salmonella serotypes that can cause a variety of diseases in different hosts.

Salmonella serotype associated with poultry reproductive tissues that have public health concern include Salmonella enterica subspecies enterica serovar Enteritidis, Salmonella enterica subspecies enterica serovar Typhimurium. Among the different serotypes, Salmonella Enteritidis may be better able to achieve invasion and as a consequence may be found more frequently in reproductive tissues which causes fowl paratyphoid (Mahmud, 2015). Fowl paratyphoid is generally a subclinical infection of all domestic poultry and game birds throughout the world and has also been reported in many different species of wild birds (Mark et al., 2008). The numerous motile members of the bacterial genus Salmonella are often referred to collectively as paratyphoid (PT) salmonellae. These organisms can infect a very wide variety of hosts (including invertebrate and vertebrate wildlife, domestic animals, and humans) to yield either asymptomatic intestinal carrier or clinical diseases (Saif, 2008).

The invA gene is functionally involved with invasion of intestinal cells of the host which codes the protein in the inner bacterial membrane (Rahn et al., 1992). The invA gene has been reported as a specific PCR target with important diagnostic tools for the genus Salmonella because it posses the unique sequence specific for the genus (Rahn et al., 1992; Malorny et al., 2003; Li et al., 2012). Moreover, another gene named IE1 has been reported as specific for Salmonella Enteritidis (Wang and Yeh, 2002; Silva et al., 2011; Paião et al., 2013). Most of the researches on natural infection of Salmonella in layers were done in Bangladesh using the methods of necropsy and histopathology, and isolation of Salmonella by culture in media, staining and sugar fermentation tests, and experimental pathogenesis, pathology and vertical transmission in chickens (Haider et al., 2004; Hossain et al., 2006; Islam et al., 2007; Haider, et al., 2008). However, very few investigations have been performed for isolation, molecular detection of Salmonella available in Gazipur, Bangladesh (Hosen et al., 2019). In order to control the PT Salmonella infection in poultry as well as to protect the poultry industry, histopathogical, biochemical and molecular identification need to be performed from the isolates those are endemic at Gazipur district of Bangladesh (Saha, 2012). Considering all the aspects, in the present study we have tried to observe the prevalence of PT Salmonella in chickens at Gazipur and to study the gross and histopathological changes in tissues in chickens as well. Moreover, we have performed the cultural, biochemical and molecular detection of the Salmonella Enteritidis by PCR using targeting invA and IE1 gene. Because, these two genes are allele specific for Salmonella Enteritidis detection.

\section{Materials and Methods}




\section{Collection of poultry samples}

A total of 150 (one hundred fifty) poultry samples including 30 sick birds on the basis of clinical signs of PT, 70 apparently healthy birds and 50 dead birds from 10 commercial layer farms were randomly collected from different areas of Gazipur district, Bangladesh during the period of September'16 to June'17. At the Post mortem examination, a systemic dissection was made along with that the gross changes in different tissues were recorded. After necropsy representative samples like lungs, liver, spleen, heart, kidney, caecal tonsils, intestine and ovary were collected in $10 \%$ buffer formalin for histopathology.

\section{Collection of bacteriological samples}

Liver, spleen, lungs and intestinal swab samples were collected from 150 chickens during necropsy. The total swab samples were 600. Aseptic cotton swabs were used and all the swabs were collected in test tubes containing $10 \mathrm{ml}$ tetrathionate broth (TTB) according to methods as described previously (Haider et al., 2008).

\section{Cultural media}

After collection, at first, all the bacteriological samples were incubated for 24 hours in TTB. The samples were primarily cultured in Nutrient agar and then sub-cultured in the Salmonella-Shigella (SS) agar, XLD agar, Triple sugar iron (TSI) agar, Brilliant green agar (BGA) and Eosine methylene blue (EMB) agar to get desired single colony (Haider et al., 2008).

\section{Morphological characterization}

The presumptive colonies of suspected bacteria in various media were characterized microscopically using Gram's stain. For the separation of motile and non-motile bacteria, motility test was performed using hanging drop slide method (Cowan, 1965).

\section{Carbohydrate fermentation test ability and biochemical test}

Nine important sugars such as glucose, sucrose, lactose, mannitol, dulcitol, arabinose, inositol, xylose and maltose were used for sugar fermentation test (Cowan, 1965). The biochemical identification of PT Salmonella was performed using inositol and TSI agar slant (Cowan, 1965).

\section{Processing and staining of issues}

Tissue samples collected from intestine, liver, lungs, spleen, heart and ovary were fixed in $10 \%$ neutral buffered formalin and further processed for histopathological staining with hematoxylin and eosin stains (Mashkoor et al., 2013). Photomicrography of stained tissues was taken using photomicrographic camera (ZEISS AxioCam ERc5s).

\section{Molecular identification of presumptive} isolates

From the isolated pure culture the genomic DNA of PT Salmonella was extracted using DNA extracting kits (Promega Corp. Madison, WI, USA) (Haider et al., 2008). Extracted DNA was amplified with using primers invA and IE1 (Table 1) targeting for the gene of Salmonella Spp. using commercial PCR kits in gene amplification PCR system 9600 Thermocycler (eppendorf, Germany) (Silva et al., 2011; Shanmugasamy et al., 2011). The thermal profile of PCR for InvA gene was $94^{\circ} \mathrm{C}$ for 5 minutes (initial denaturation), $94^{\circ} \mathrm{C}$, for 20 second (denaturation), $50^{\circ} \mathrm{C}$ for 30 second (annealing), $72^{\circ} \mathrm{C}$ for 30 second (elongation) and $72^{\circ} \mathrm{C}$ for 7 minutes (final 
Table 1. Primers were used for the detection of the Salmonella spp

\begin{tabular}{lllc}
\hline Primers & Length & \multicolumn{1}{c}{ Primer sequence $\left(5^{\prime}-3^{\prime}\right)$} & Amplification products $(\mathrm{bp})$ \\
\hline invA(F) & 26 & GTGAAATTATCGCCACGTTCGGGCAA & 284 \\
$\operatorname{invA(R)}$ & 22 & TCATCGCACCGTCAAAGGAACC & 316 \\
IE1(F) & 20 & AGT GCC ATA CTT TTA ATG AC & \\
IE1 (R) & 19 & ACT ATG TCG ATA CGG TGG G & \\
\hline
\end{tabular}

extension), and the holding temperature was $4^{\circ} \mathrm{C}$. Separation of amplified products were done by electrophoreses on $1.5 \%$ agarose gel containing $5 \mu \mathrm{g}$ per $\mathrm{ml}$ ethidium bromide with a $100 \mathrm{bp}$ ladder as molecular weight marker (Haider et al., 2008).

\section{Results and Discussion}

In this study, collected chickens were subjected to bacteriological isolation and identification, gross and histopathological study of identified cases. One hundred and fifty samples were collected from 10 different layer farms of Gazipur district.

\section{Prevalence of isolated and identified PT Salmonella}

Among 150 chickens' samples, 99 were found PT Salmonella positive based on colony characters on different agar media and sugar fermentation tests. So, the prevalence of salmonellosis in this study was $66 \%$. The prevalence rates in different organs of chickens were found different (Table 2). The highest prevalence was found in intestinal swabs followed by liver, spleen and lungs. The prevalence of salmonellosis detected in this study is similar to the findings of other researcher (Islam et al., 2016). Rahman et al., 2011 reported that the overall seropositive prevalence of Salmonella was $46.2 \%$ in Birgonj upazila, Dinajpur district in Bangladesh. The prevalence rate is slightly higher in this study than that of the findings of Rahman et al., 2011. Densely populated poultry farming in this experimental area could be the major cause of higher prevalence of salmonellosis which was supported by Donado-Godoy et al., 2012. Donado-Godoy et al., 2012 reported that Salmonella was isolated from $41 \%$ of farms and $65 \%$ of the 315 chicken houses sampled in Colombia.

\section{Colony characters in cultural media}

Isolated organisms were formed round, white dew drop like colonies on nutrient agar (Fig. 1a). The organisms were formed round, raised, transparent single colonies with black centers on SS agar (Fig. 1b). On XLD agar, PT Salmonella was produced black colonies

Table 2. Cultural prevalence of PT Salmonella of collected samples in different organs

\begin{tabular}{lcccc}
\hline Organs \& & site of swabs & Total swabs & Positive & Cultural Prevalence \% \\
\hline Liver & 150 & 45 & 30 \\
Spleen & 150 & 35 & 23.33 \\
Lungs & 150 & 15 & 10 \\
Intestine & 150 & 75 & 50 \\
\hline
\end{tabular}


(Fig. 1c). Black colonies were found on TSI medium (Fig. 1d). Red to pink white colonies was surrounded by brilliant red zones formed on BGA media (Fig. 1e). Pink colonies were showed by PT Salmonella in EMB agar (Fig. 1f). In the present study the colony characters of Salmonella, the production of hydrogen sulfide gas with black colonies on SS agar and TSI agar are similar to the results of other authors (Hossain et al., 2008; Saha et al., 2012; Lujain et al., 2016).

\section{Morphological characterization}

All the isolates were showed Gram's negative, rod shaped pink color bacilli with Gram's staining which was similar to the findings of other authors (Haider et al., 2004; Rahman et al., 2011; Lujain et al., 2016). Organisms were found motile when examined under microscope with hanging drop slide preparation that confirmed as PT Salmonella. This finding was supported by others (Haider et al., 2004).

\section{Biochemical tests}

A total of 170 isolates were purified and tested for biochemical identification. The isolated organisms fermented inositol, dextrose, maltose, xylose, mannitol, arabinose and dulcitol but did not ferment the sucrose and lactose. In TSI agar slant the organisms produced $\mathrm{H}_{2} \mathrm{~S}$ gas. The similar sugar fermentation tests were reported previously (Haider et al., 2004; Ahmed et al., 2008).

\section{Gross lesions}

Liver was congested and there was focal necrosis (Fig. 2a). Button like ulceration was
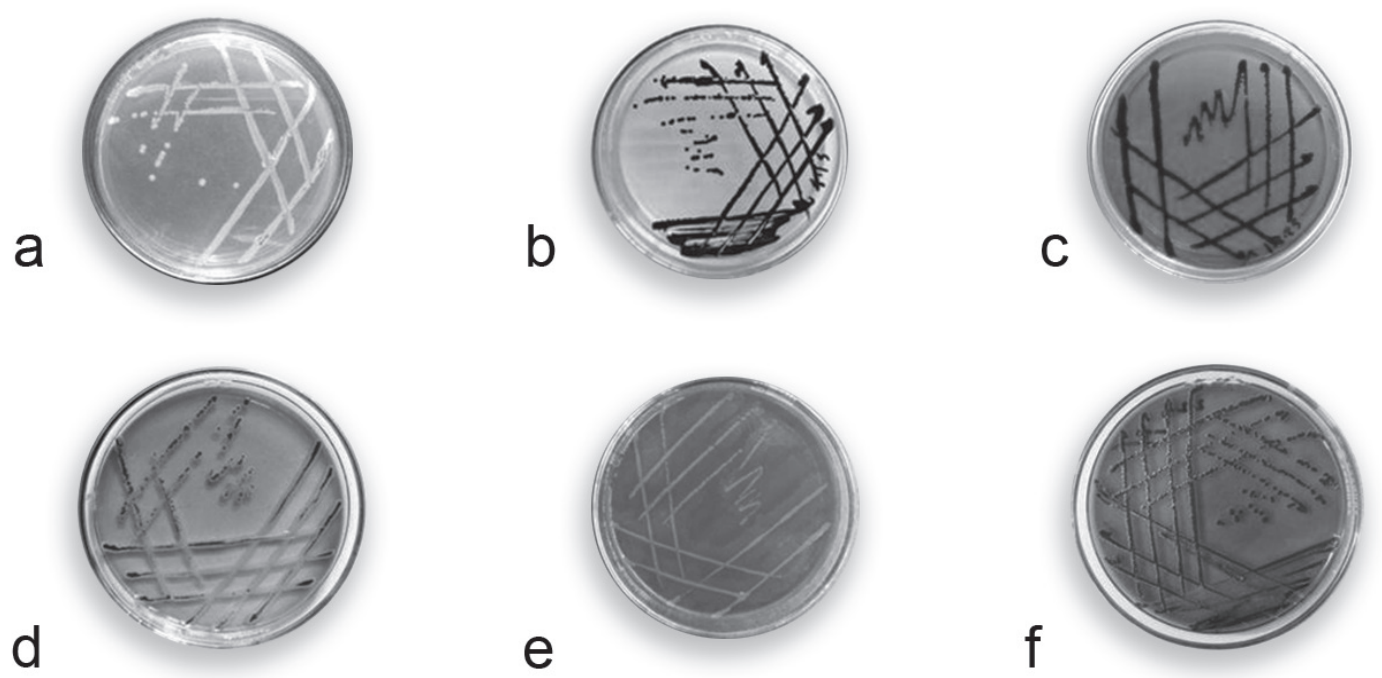

Fig. 1. a. Colonies of isolated Salmonella on Nutrient agar plate. b. Organism formed round, raised, transparent single colonies with black centers on SS agar. c. Salmonella produced black colonies on XLD agar plate. d. Isolated Salmonella produced black colonies on TSI medium. e. Colonies are small, opaque, pink or white on Brilliant Green (BG) agar. f. Pink color colonies of Salmonella spp. are on EMB agar. 
recorded in caecal tonsils (Fig. 2b). Petechial hemorrhages were found in the spleen (Fig. 2c) and base of the heart. The ova were hemorrhagic, deformed and cystic (Fig. 2d). Profuse hemorrhage was found in intestine (Fig. 2e). Petechial hemorrhages were also found in the kidneys (Fig. 2f). In this study, grossly the liver and spleen samples were infected by Salmonella spp showed congestion with focal necrosis which was similar to the findings of other authors (Hoop et al., 1993; Majid et al., 2000; Rahman et al., 2011; Nazir et al., 2012; Saha et al., 2016). Profuse hemorrhage and congestion in the intestine which were correlated to the findings of other authors (Hoop et al., 1993;
Majid et al., 2000; Nazir et al., 2012). The ovarian follicles were found congested and misshapen which had been reported earlier (Majid et al., 2000; Ahmed et al., 2008; Nazir et al., 2012).

\section{Microscopic Lesions}

The lesions of small intestine included severe congestion and infiltration of inflammatory cells (Fig. 3a). The prepared histopathological slide of liver section showed vascular congestion, multifocal degeneration and necrosis of hepatocytes, and infiltration of heterophils and nodular lesions with infiltration of macrophages (Fig. 3b and Fig. 3c). Section of spleen showed severe congestion and
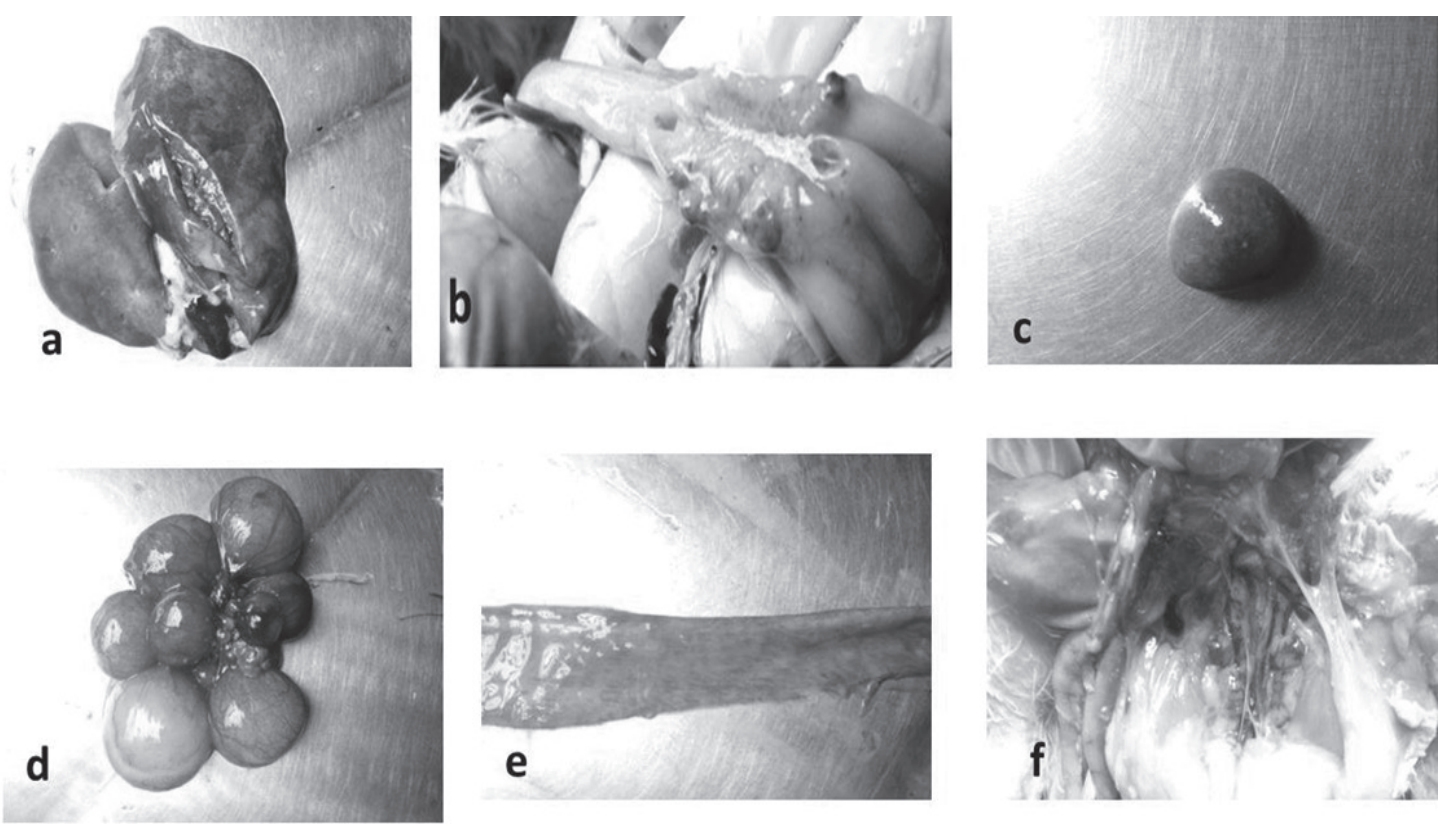

Fig. 2. a. Congested liver with focal necrosis of Salmonella infected chickens. b. Caecal tonsil showing button like ulceration in case of Salmonella infected chickens. c. Spleen of Salmonella infected chickens showing petechial hemorrhage and focal necrosis. d. Ova are shown hemorrhagic, deformed and cystic in Salmonella infected chickens. e. Salmonella infected chicken's small intestine showing profuse hemorrhage and congestion. f. Salmonella infected chickens kidneys showing petechial hemorrhage. 
focal necrosis (Fig. 3d). Pulmonary lesions described that there was congestion in blood vessels and sero-fibrinous exudation in lungs (Fig. 3e). The ovary showed congestion and infiltration of inflammatory cells (Fig. 3f). The section of heart showed necrosis of the myofibers and few infiltrations of heterophils (Fig. 3g). Similar histopathogical lesions were also previously reported by others (Majid et al., 2000; Haider et al., 2004; Hossain et al., 2006; Ahmed et al., 2008; Rahman et al., 2011; Nazir et al., 2012).

\section{Molecular Characterization by PCR}

From the 170 biochemically confirmed PT positive samples, 12 presumptive salmonella were selected randomly for molecular identification. A PCR product of 284 bp was successfully amplified with PCR which is a fragment of invA gene specific for all members of Salmonella species. 100 bp DNA marker was used as a molecular weight marker. The band size detected in 11 of the presumptive Salmonella isolates (91.7\%) and analyzed by agarose gel electrophoresis (Fig. 4). Again
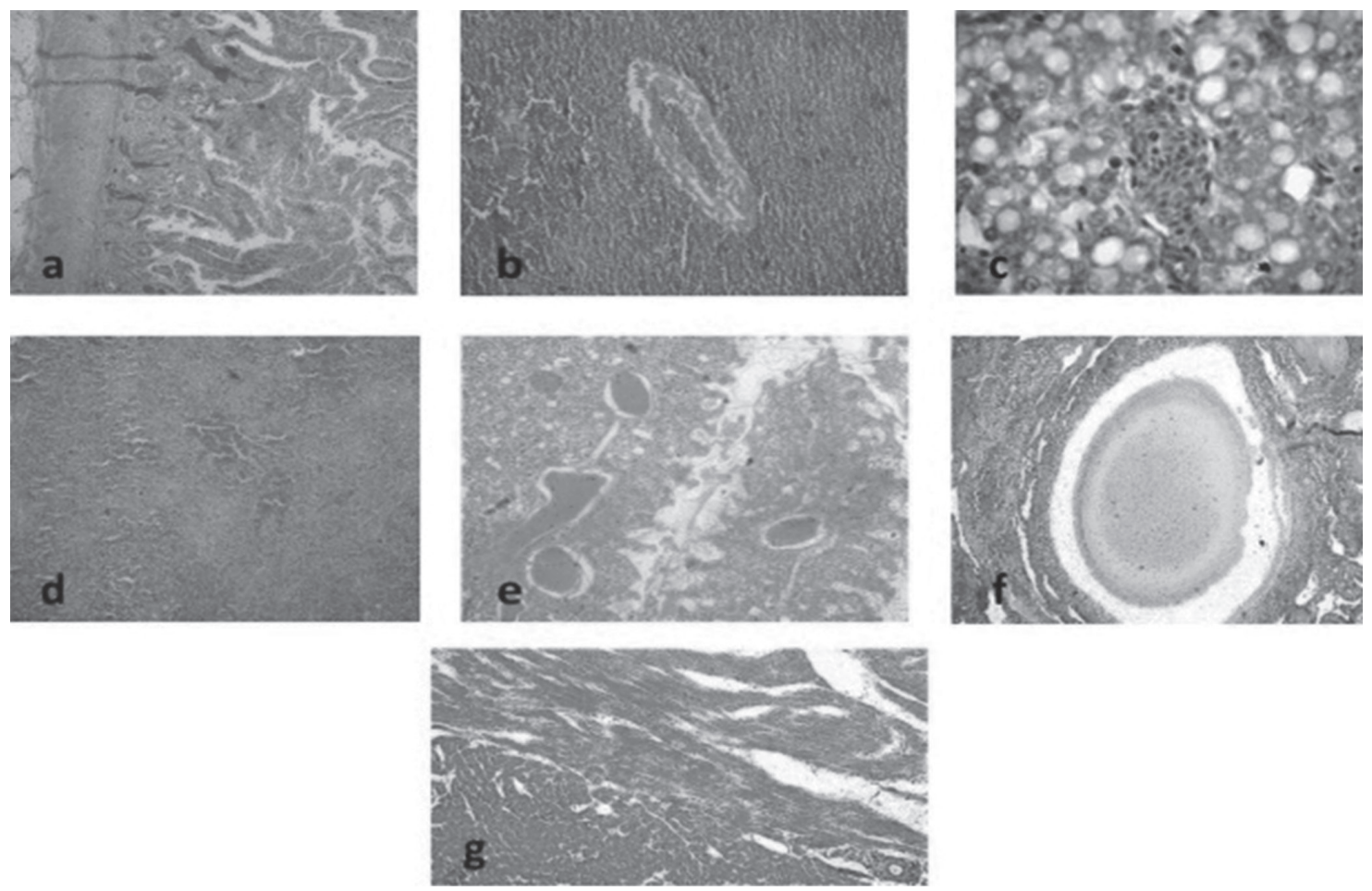

Fig. 3. a. The lesions of small intestine included severe congestion and infiltration of inflammatory cells, (H \& E, X 100). b. Section of liver section showed vascular congestion, multifocal degeneration and necrosis of hepatocytes and infiltration of heterophils, (H \& E, X100). c. Section of liver is showing $\mathrm{RBC}$ in central veins, $(\mathrm{H} \& \mathrm{E}, \mathrm{X} 400)$. d. Section of spleen showed severe congestion and focal necrosis, $(H \& \mathrm{E}, \mathrm{X100})$. e. Pulmonary lesions described that there was congestion in blood vessels and sero-fibrinous exudation in lungs, (H \& E, X 100). f. Section of ovary shows congestion and infiltration of inflammatory cells (H \& E, X 100). g. Section of heart showing necrosis of the myofibers and few infiltrations of heterophils, (H \& E, X 100). 


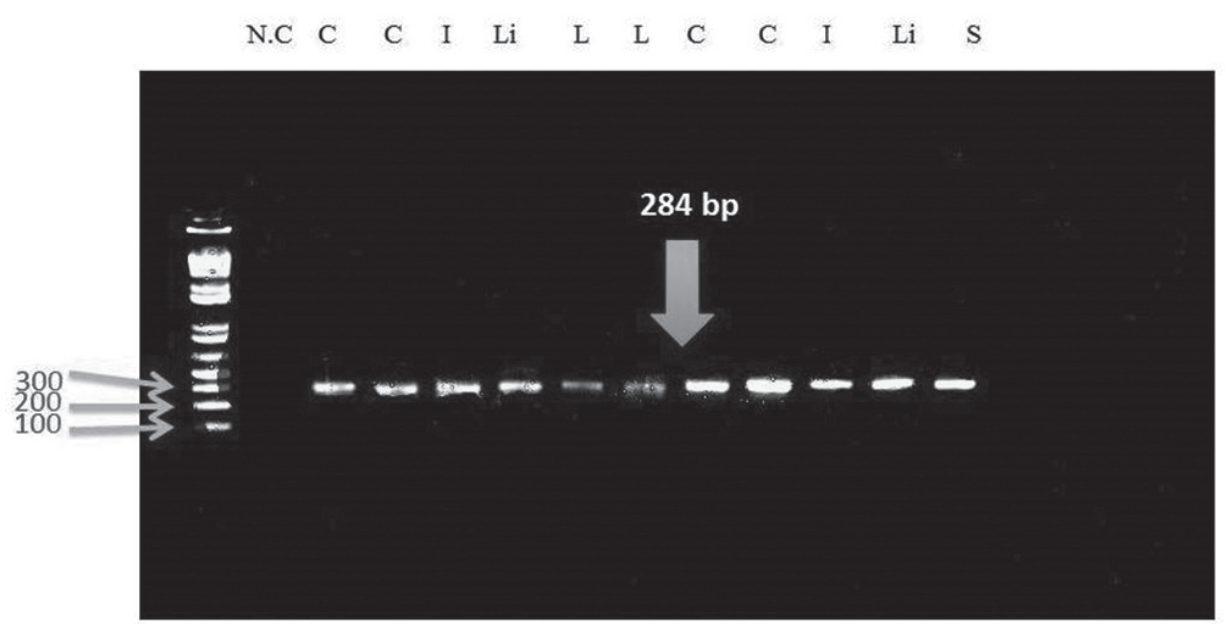

Fig. 4. Agarose gel electrophoresis for amplification of invA gene (284bp) of Salmonella spp. (Legends- $\mathrm{C}=$ Cloacal swabs, $\mathrm{L}=$ Lungs swabs, $\mathbf{L} \mathbf{i}=$ Liver swabs, $\mathrm{I}=$ Intestinal swabs, $\mathrm{S}=$ Spleen swabs, N.C. = Negative Control).

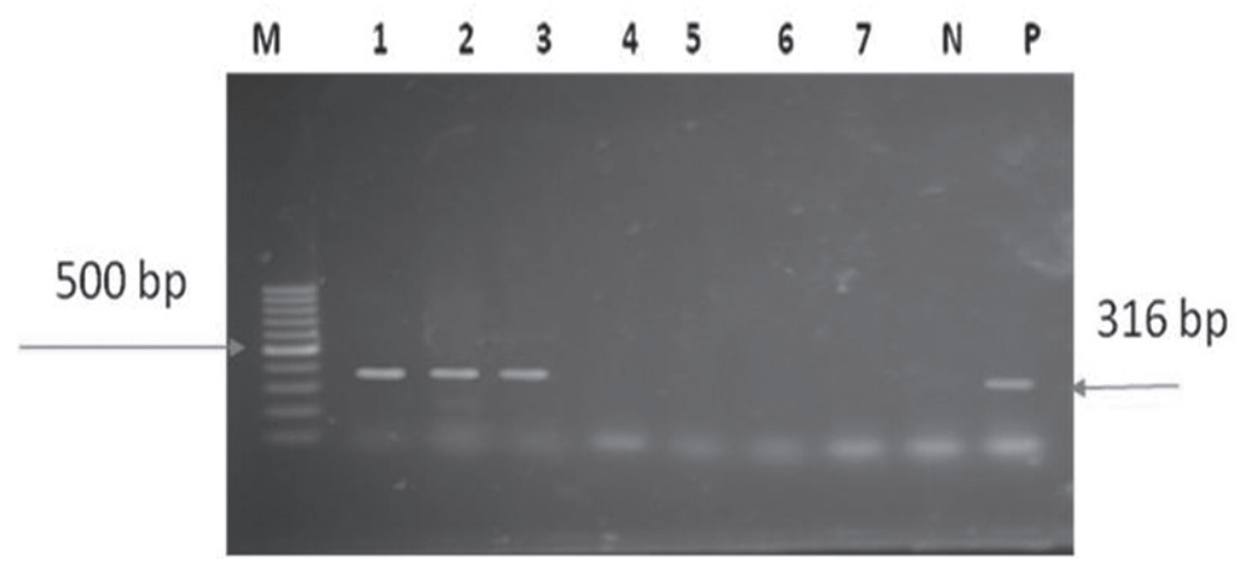

Fig. 5. Amplification of IE-1 gene (316 bp specific genomic primer; Lane M: 100 bp DNA ladder, Lane P: positive control Lane N: Negative control, Lane 1-3 DNA templates extracted from culture positive (Positive control was taken from Department of Microbiology and Public Health, BSMRAU, Gazipur).

all the invA positive samples were positive for the IE-1 gene (band size 316 bp) (Fig. 5) which revealed the isolates were Salmonella Enteritidis. In recent study, 91.7\% samples were confirmed as Salmonella spp by PCR which was confirmed earlier by biochemical tests. The percentage samples were lower than that of other finding (Malorny et al., 2008). It may be due to the failure of DNA extraction from the isolates. Primers invA is a rapid, sensitive, and definite for the detection of Salmonella spp in many clinical samples (Lampel et al., 2000). Shanmugasamy et al., 2011 supported the ability of these 
specific primer sets to confirm the isolates as Salmonella spp. In this study, all the Salmonella spp. were identified as Salmonella Enteritidis when specific IE1 primer was used which suggests that $100 \%$ specificity of IE1 gene in case of detection of Salmonella Enteritidis. This finding are in agreements with other studies (Wang and Yeh, 2002; Silva et al., 2011).

Although Gazipur is considered as the prime zone for poultry industry in Bangladesh. There is no such satisfying research work on PT Salmonella. The prevalence of PT Salmonella which is not only important for producing hazard free poultry products but it has also zoonotic importance. Our research work will help to identify the PT Salmonella at farmer level with minimum lab facilities by rapid sensitive PCR, cultural and biochemical methods. It will be helpful for sustainable poultry production. Molecular detection will also help the researchers who are intended to do further research on Salmonella.

\section{Conclusion}

Fowl paratyphoid is generally a subclinical infection of all domestic poultry and game birds. Salmonella Enteritidis is one of the many causal agents of this disease which has zoonotic importance. The histopathology of fowl paratyphoid, isolation and molecular detection of its causal agent as Salmonella spp. were conducted in this study. The prevalence of the salmonellosis was found $66 \%$. The gross and histopathological lesions were shown the severity of paratyphoid infections in chickens. The severity may be enhanced by the combination of other diseases like collibacillosis, mycoplasmosis and mycotoxicosis in the densely poultry populated area. Besides, these PT Salmonella can cause huge public health hazards in experimental area.

\section{Acknowledgements}

This research work was funded by Research Management Wing (RMW) and University Grant Commission, Bangabandhu Sheikh Mujibur Rahman Agricultural University, Gazipur.

\section{References}

Ahmed, K. M., M. T. Islam, M. G. Haider and M. M. Hossain. 2008. Seroprevalence and pathology of naturally infected Salmonellosis in poultry with isolation and identification of causal agents. $J$. Bangladesh Agri. Univ. 6(2): 327-334.

Cowan, S. T. 1965. Cowan and Steel's Manual for the Identification of Medical Bacteria. (ed.) Cambridge University Press, UK.

Donado-Godoy, P., I. Gardner, B. A. Byrne, M. Leon, E. Perez-Gutierrez, M. V. Ovalle, M. A. Tafur and W. Miller. 2012. Prevalence, risk factors, and antimicrobial resistance profiles of Salmonella from commercial broiler farms in two important poultryproducing regions of Colombia. J. Food Prot. 75(5): 874-883.

Haider, M. G., E. H. Chowdhury, M. A. H.N. A. Khan, M. T. Hossain and M. S. Rahman. 2008. Experimental pathogenesis of pullorum disease with the local isolate of Salmonella enteric serovar. enterica subspecies pullorum in pullets in Bangladesh. Korean J. Poult. Sci. 35: 341-350.

Haider, M. G., M. G. Hossain, M. S .Hossain, E. H. Chowdhury, P. M. Das and M. M. Hossain. 2004. Isolation and characterization of 
Enterobacteria associated with health and disease in sonali chickens. Bangladesh $J$. Vet. Med. 2(1): 15-21.

Hoop, R. K. and A. Pospischil. 1993. Bacteriological, serological, histological and immunohistochemical findings in laying hens with naturally acquired Salmonella Enteritidis phage type 4 infections. Vet. Record. 133: 391-393.

Hosen, J., M. M. Rahman, J. Alam, Z. C. Das, M. A. H. N. A. Khan and M. G. Haider. 2019. Pathology of fowl typhoid and molecular detection of its pathogen. Ann. Bangladesh Agric. 23(2):49-60.

Hossain, M. S., E. H. Chowdhury, M. M. Islam, M. G. Haider and M. M. Hossain. 2006. Avian Salmonella infection: Isolation and identification of organism and histopathological study. Bangladesh $J$. Vet. Med. 4(1): 07-12.

Islam, M. J. A., A. T. M. Elahi, T. Ahmed and M. K. Hasan. 2016. Isolation and identification of Salmonella spp. from broiler and their antibiogram study in Sylhet, Bangladesh. J. Appl. Biol. Biotech. 4(03): 46-51.

Islam, M. K. 2014. Challenges and prospects of poultry industry in Bangladesh. European J. Busi. Managemt. 6(7): 116-127.

Islam, M. M., M. M. Hossain, M. G. Haider, E. H. Chowdhury and M. Kamruzzaman. 2007. Seroprevalence and pathological study of Salmonella infections in layer chickens and isolation of causal agents. Pp. 9-15. In Proceedings of the 5th International Poultry show and seminar, China Friendship Conference Centre (CFCC), Sher-e- Bangla Nagar, Dhaka, Bangladesh.

Karim, M. J. 2003. Current disease pattern in poultry with special emphasis on parasites and their methods of control. Pp. 119123. Proceeding of the 3rd International Poultry Show and Seminar of World Poultry Science Association-Bangladesh Branch. BCFCC, Dhaka, Bangladesh.
Karmi, M. 2013. Detection of virulence gene (InvA) in Salmonella isolated from meat and poultry products. Int. J. Gen. Genom. 3: 7-12.

Lampel, K. A., P. A. Orlandi and L. Kornegay. 2000. Improved template preparation for PCR- based assay for detection of foodborne bacterial pathogens. Appl. Environ. Microbiol. 66: 4539- 4542.

Li, Q., W. Cheng, D. Zhang, T. Yu, Y. Yin, H. Ju and S. Ding. 2012. Rapid and sensitive strategy for Salmonella detection using an InvA gene-based electrochemical DNA sensor. Int. J. Electrochem. Sci. 7: 844-856.

Lujain, D. A. K. and D. E. J. Khammas. 2016. Detection of Salmonellae isolated from layer and broiler chickens sample by using Polymerase Chain Reaction Technique. International J. Adv. Res. Biol. Sci. 3(8): 104-108.

Mahmud, M. S. 2015. Prevalence Salmonella spp. in Poultry Eggs from Different Retail Markets of Savar Area, Bangladesh. American J. Food Sci. Health. 1(2): 27-31.

Majid, A., M. Siddique and A. Khan. 2000. Avian Salmonellosis: Gross and Histopathological lesions. Pakistan Vet. J. 20(04): 183-186.

Malorny, B., J. Hoorfar, C. Bunge and R. Helmuth. 2003. Multicenter validation of the analytical accuracy of Salmonella PCR: towards an international standard. Appl. Environ Microbiol. 69: 290-296.

Mark. P., F. M. Paul, M. B. Janet and J. A. Dennis. 2008. Poultry Diseases. (6th ed.) Saunders Ltd.

Mashkoor, J. A. K., M. Z. Khan, R. Z. Abbas, M. K. Saleemi and F. Mahmood. 2013 Arsenic induced clinico-hemato-pathological alterations in broilers and its attenuation by vitamin E and selenium. Pakistan J. Agri. Sci. 50: 131-138.

Nazir, S., K. S. Ahmad, D. M. Maqbool, M. M. Saleem, K. F. Ahmad and A. Amare. 2012. 
Pathology of Spontaneously Occurring Salmonellosis in Commercial Broiler Chickens of Kashmir Valley. J. World Poult. Res. 2(4): 63-69.

Paião, F. G., L. G. A. Arisitides, L. S. Murate, G. T. Vilas-Bôas, L. A. Vilas-Boas and M. Shimokomaki. 2013. Detection of Salmonella spp, Salmonella Enteritidis and Typhimurium in naturally infected broiler chickens by a multiplex PCRbased assay. Brazilian J. Microbiol. 44(1): 37-41.

Rahman, M., A. B. M. Shahinuzzaman, A. K. Saha, M. A. Sufian, M. Rahman and M. Hossain. 2011. Prevalence of Salmonella infection in naturally infected layer of birds in Bangladesh. The Bangladesh Vet. 28(1): 8-18.

Rahman, M. M., A. Z. Rahman and M. S. Islam. 2007. Bacterial diseases of poultry prevailing in Bangladesh. Res. J. Poult. Sci. 1(1): 1-6.
Rahn, K., S. A. De Grandis, R. C. Clarke, S. A. McEwen and J. E. Galan. 1992. Amplification of an invA gene sequence of Salmonella typhimurium by polymerase chain reaction as a specific method of detection of Salmonella. Mole. Cell. Prob. 6: 271-279.

Saha, A. K., M. A. Sufian, M. I. Hossain and M. M. Hossain. 2012. Salmonellosis in layer chickens: pathological features and isolation of bacteria from ovaries and inner content of laid eggs. J. Bangladesh Agril. Univ. 10(1): 61-67.

Saif, Y. M. 2008. Disease of Poultry. (12th ed.) 2121 State Avenue, Ames, Iowa 50014, USA: Blackwell Publishing Professional.

Shanmugasamy, M., T. Velayutham and J. Rajeswari. 2011. InvA gene specific PCR for detection of Salmonella from broilers. Vet. World. 4(12): 562-564.

Silva, S. P. D., C. Thayse, M. Marciane, J. Alves, A. Hirooka, E. Y. Elisa and C. T. R. M. 
